\title{
Resource Allocation Strategy and Soil Driving Factors of Vegetation Concrete Restoration System Under Co-Operating Environment
}

\author{
Mingyi Li*(**), Wennian Xu*(**), Zhenyao Xia*(**), Yanyan Shao*, Yueshu Yang* and Hai Xiao*(**)† \\ * Key Laboratory of Geological Hazards on Three Gorges Reservoir Area (China Three Gorges University), Ministry of \\ Education, Yichang, 443002, People's Republic of China \\ ** Engineering Research Center of Eco-environment in Three Gorges Reservoir Region, Ministry of Education, China \\ Three Gorges University, Yichang, 443002, People's Republic of China \\ †Corresponding author: Hai Xiao; oceanshawctgu@163.com
}

Nat. Env. \& Poll. Tech. Website: www.neptjournal.com

Received: 29-05-2020

Revised: 23-07-2020

Accepted: 31-07-2020

Key Words:

Disturbed slope

Vegetation concrete

Ecological restoration

Biomass

Soil factor

\begin{abstract}
The ecological function optimization strategy of vegetation directly affects the self-stability and engineering sustainability of the vegetation concrete ecological restoration system, which is the key to the successful restoration of an ecosystem. To clarify the survival strategies of slope protection plants and their response mechanisms to the soil environment in the process of vegetation concrete ecological restoration, the resource allocation strategies and soil driving factors of typical slope protection plants, such as Cynodon dactylon (Linn.) Pers. and Indigofera amblyantha, in a co-operation environment mode, were investigated by controlled simulation experiments. The results showed that (1) the cooperating environmental model had a significant effect on the biomass (leaf, stem and root) and root shoot ratio of slope protection vegetation; (2) the sensitivity of plant biomass in the co-operating environmental model was leaf biomass ratio > root biomass ratio > stem biomass ratio, and the most sensitive organ was the leaf; (3) a common allometric growth index for the plants of all slopes existed, the root and leaf grew at the same rate, and the plant roots and stems showed allometric growth with the synergistic effect of rainfall and slope; (4) the total nitrogen content of soil had a significant correlation with the vegetation R/S (root shoot ratio) $(p<0.05)$ due to the synergistic effect of vegetation type and slope, while the total phosphorus content of the $\mathrm{P} 3$ slope had a significant negative correlation with the vegetation R/S $(p<0.05)$. The co-operating environmental model significantly affected the spatial distribution of vegetation biomass and had the greatest impact on leaf biomass. The contents of soil nitrogen and phosphorus were the key soil driving factors that affected the distribution pattern of plant biomass. The resource allocation characteristics of different vegetation and its response to soil factors

had species specificity.
\end{abstract}

\section{INTRODUCTION}

With the increasing attention to the ecological environment, the former extensive slope protection and engineering construction mode cannot meet the requirements of ecological green sustainable development. Vegetation concrete slope treatment method has realized the organic combination of mechanical stability and ecological function, it has become one of the most extensively applied ecological slope protection substrate (Wang et al. 2020, Xu et al. 2012).

The growth of vegetation, and positive and stable succession of its community are key to the success of ecosystem restoration (Norton \& Young 2016). However, the stress factors in the slope vegetation restoration system are often unfavourable to plant growth, which hinders ecological restoration (Zhang et al. 2017). The optimal allocation of the resources of plants in adverse conditions is a basic strategy for protecting plants against environmental stress (Fang et al. 2012, Cao \& Chen 2015). The allocation strategy of plant biomass is regulated by multiple factors (Daniel et al. 2014). Changes in environmental factors often affect the absorption and transportation of nutrients by changing the physical and chemical properties of soil, which causes a difference in the growth strategies between the root system and the aboveground part of a plant. There are few studies on the influence of a co-operating environmental model on the vegetation resource allocation strategy and soil driving mechanism of vegetation concrete ecological restoration.

In this paper, resource allocation strategy and soil driving factors of vegetation concrete restoration system under the influence of slope, precipitation and vegetation type is investigated. The purpose of this study is to solve three scientific problems: (1) Does specificity exist in the biomass allocation of different functional plants? (2) What is the relationship between the heterogenic growth rate of slope protection plants and co-environmental factors? 
(3) What are the strategies of plant biomass allocation and the response mechanism to the soil environment in the process of ecological restoration? The study of the response mechanism of a vegetation resource allocation strategy to soil factors and allometric growth relationship has guiding significance for clarifying the ecological function optimization strategy of vegetation, consolidating and improving the restoring ecological system function, and realizing the stability and sustainability of slope restoration.

\section{MATERIALS AND METHODS}

\section{Materials}

The experimental site was located in China Three Gorges University $\left(30^{\circ} 43^{\prime} \mathrm{N} ; 111^{\circ} 18^{\prime} \mathrm{E}\right)$. Typical vegetation, Cynodon dactylon (Linn.) pers. and Indigofera amblyantha, which are commonly employed in a slope protection project, were chosen as the experimental vegetation. The test soil is the Yellow Soil from the surface of the cultivated land of Nanjinguan slope of Yichang City. According to the local rock content distribution, the test rock was obtained from Xiazhou Avenue in Yichang City, and the material was sandstone.

\section{Experimental Design}

Seven experimental models were constructed based on different environmental modes of vegetation type (combination of herbs, shrubs and grass irrigation), slope $\left(45^{\circ}, 60^{\circ}\right.$ and $\left.75^{\circ}\right)$ and precipitation $(10 \mathrm{~mm}, 15 \mathrm{~mm}$, and 20 $\mathrm{mm})$. The size of each model was $2 \mathrm{~m} \times 2 \mathrm{~m}$; the thickness of the argillaceous sandstone was $20 \mathrm{~cm}$, and the thickness of vegetation concrete was $10 \mathrm{~cm}$. There is a certain proportion on the mass of each component during the vegetation concrete collocation. When $100 \mathrm{~kg}$ of planting soil is used, $6 \mathrm{~kg}, 8 \mathrm{~kg}$ and $3 \mathrm{~kg}$ of cement, organic matter and activation additive are used respectively. The vegetation concrete is laid in two layers of base $(8 \mathrm{~cm})$ and surface layer $(2 \mathrm{~cm})$. There are no plant seeds in the base layer, and the surface

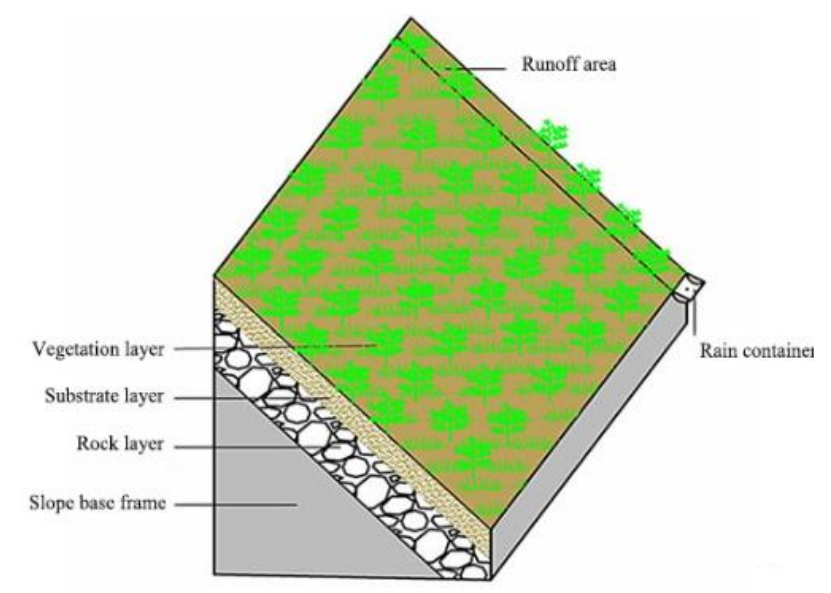

Fig. 1: Structural diagram of the slope system.

layer is planted with single or mixed plant seeds according to $15 \mathrm{~g} / \mathrm{m}^{2}$. Table 1 gives the design of the test group and Fig. 1 shows the structural diagram of the slope system.

\section{Experimental Method}

Experimental determination: The experiment started in March 2018, and samples were collected once in the middle of March, June, September and December every year (the first year is represented by "I"; and the second year is represented by "II"). The ring knife method was employed for soil sampling. Soil organic carbon was determined by the $\mathrm{K}_{2} \mathrm{Cr}_{2} \mathrm{O}_{7}$ volumetric method and external heating method. Total nitrogen and total phosphorus were determined by the SKALAR SAN ${ }^{++}$continuous flow analyser. The aboveground parts of the plant were sampled by the quadrat harvesting method, while the underground parts of the plant roots were sampled by the root drilling method. After sampling, the samples are weighed fresh, dried at $80^{\circ} \mathrm{C}$ to a constant weight and re-weighed. The root, stem and leaf were treated with 5 replicates each.

Root shoot ratio (R/S), Leaf mass ratio (LMR), Stem biomass (SMR), Root mass ratio (RMR) and Coefficient of

Table 1: Test group design.

\begin{tabular}{|c|c|c|c|c|c|c|c|c|c|}
\hline \multirow[t]{2}{*}{ Number } & \multicolumn{3}{|c|}{ Precipitation per week $/ \mathrm{mm}$} & \multicolumn{3}{|c|}{ Vegetation allocation mode } & \multicolumn{3}{|c|}{ Slope ${ }^{\circ}$} \\
\hline & 10 & 15 & 20 & Grass & Grass + shrubs & Shrub & 45 & 60 & 75 \\
\hline P1 & & - & & - & & & & - & \\
\hline P2 & & - & & & & - & & - & \\
\hline P3 & & $\bullet$ & & & $\bullet$ & & & - & \\
\hline P4 & & & $\bullet$ & & $\bullet$ & & & $\bullet$ & \\
\hline P5 & $\bullet$ & & & & $\bullet$ & & & $\bullet$ & \\
\hline P6 & & - & & & - & & - & & \\
\hline P7 & & - & & & - & & & & - \\
\hline
\end{tabular}


Variation (CV) can be estimated by using Equation 1, 2, 3, 4 and 5 , respectively.

$$
\begin{gathered}
R / S=R B / A B \\
L M R=L B / T B \\
S M R=S B / T B \\
R M R=R B / T B \\
C V=S D / A V \times 100 \%
\end{gathered}
$$

Where, $R B$ is Root biomass of Vegetation, $A B$ is Aboveground biomass of Vegetation, $L B$ is Leaf biomass of Vegetation, $T B$ is Total biomass of Vegetation, $S B$ is Stem biomass of Vegetation, $S D$ denotes Standard deviation, $A V$ denotes Average value.

Allometric growth analysis: The allometric growth relationship can be expressed as $Y=\beta \times X^{\alpha}$, where $Y$ is a biological feature or function, $\beta$ is a standardized constant, $X$ is the individual size, and $\alpha$ is the heterogenic growth index. $\alpha=$ 1 is the isokinetic relationship, $\alpha \neq 1$ is the allometric relationship. To determine the parameters of allometric growth, the power function should be transformed into the form $\lg \mathrm{Y}=1 \mathrm{~g} \beta+\alpha \times 1 \mathrm{gX}$, and the reduced major axis (RMA, model type II) regression method should be employed to calculate the index, 95\% confidence interval (95\% CI) and determination coefficient $\left(\mathrm{R}^{2}\right)$ of the regression model. The logarithmic $\alpha$ is the slope of the linear regression after the power function logarithm, and $\lg \beta$ is the intercept of the linear regression. All these calculations were completed by SMARTR software.

Statistical analysis: The data were analysed by Excel and SPSS 22.0. Duncan analysis was performed to test the average difference and significance level of biomass for different vegetation types, slopes and precipitation models.

\section{RESULTS}

\section{Leaf Biomass}

A multivariate analysis of variance showed that the slope, vegetation type and precipitation had a significant effect on the leaf biomass of slope protection plants $(p<0.05)$. The leaf biomass of slope protection plants increased significantly with an increase in the vegetation type and reached the maximum for the condition of grass and shrub mixed planting, while the difference was not significant in the vegetation single planting mode, which indicated that the leaf biomass of plants was more sensitive to the vegetation type for the same slope and precipitation. The biomass of plant leaves increased significantly with the decline of the slope, especially for the condition of the high slope. Leaf biomass increased with an increase in precipitation; however, the increase was not obvious compared with the slope and vegetation type. The biomass of plant leaves on each slope increased gradually with time, except in winter, and reached the highest value and increased the most in autumn (Fig. 2).

\section{Stem biomass}

The synergism of the slope and precipitation had a significant effect on the stem biomass of slope protection plants $(p<$ 0.05) (Fig. 3). The stem biomass of plants increased with an increase in rainfall, reached the maximum value when the rainfall was $20 \mathrm{~mm}$. The stem biomass decreased with an increase in slope and decreased significantly when the slope was higher than $60^{\circ}$. The biomass of plant stem was the largest for the condition of grass and shrub mixed planting.

\section{Root Biomass}

Vegetation type and precipitation had a significant effect

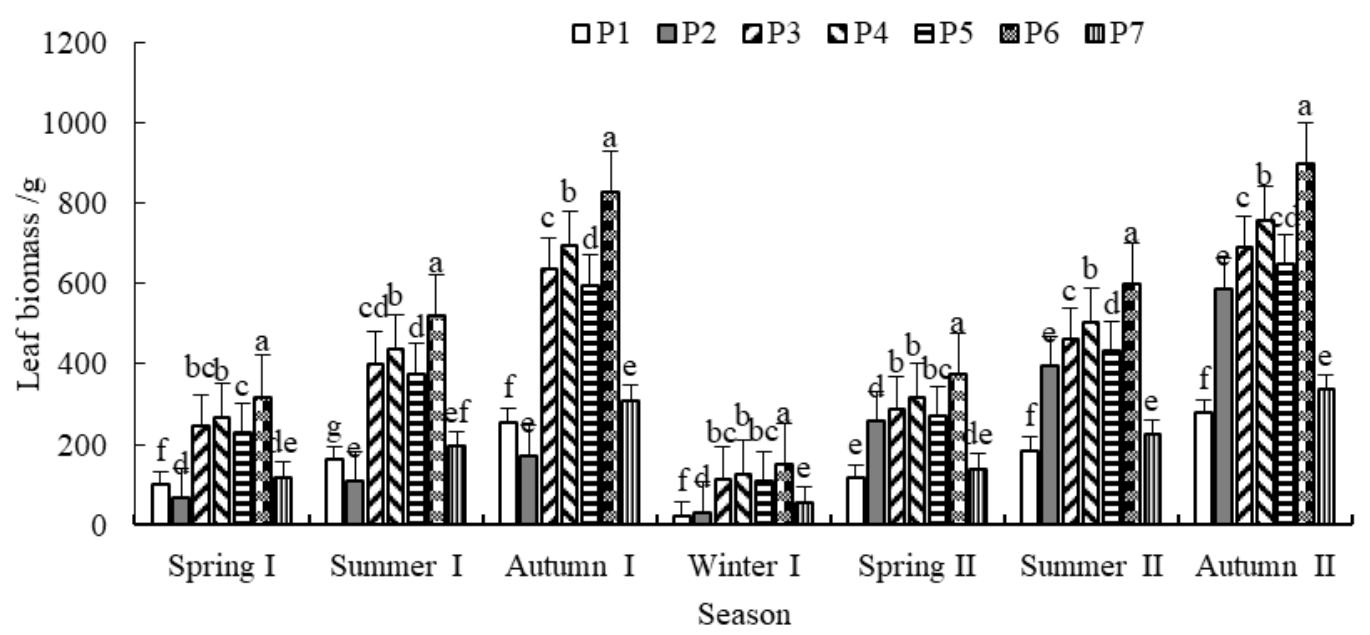

Fig. 2: Interaction of slope, vegetation type and precipitation on leaf biomass of slope protection plants. 


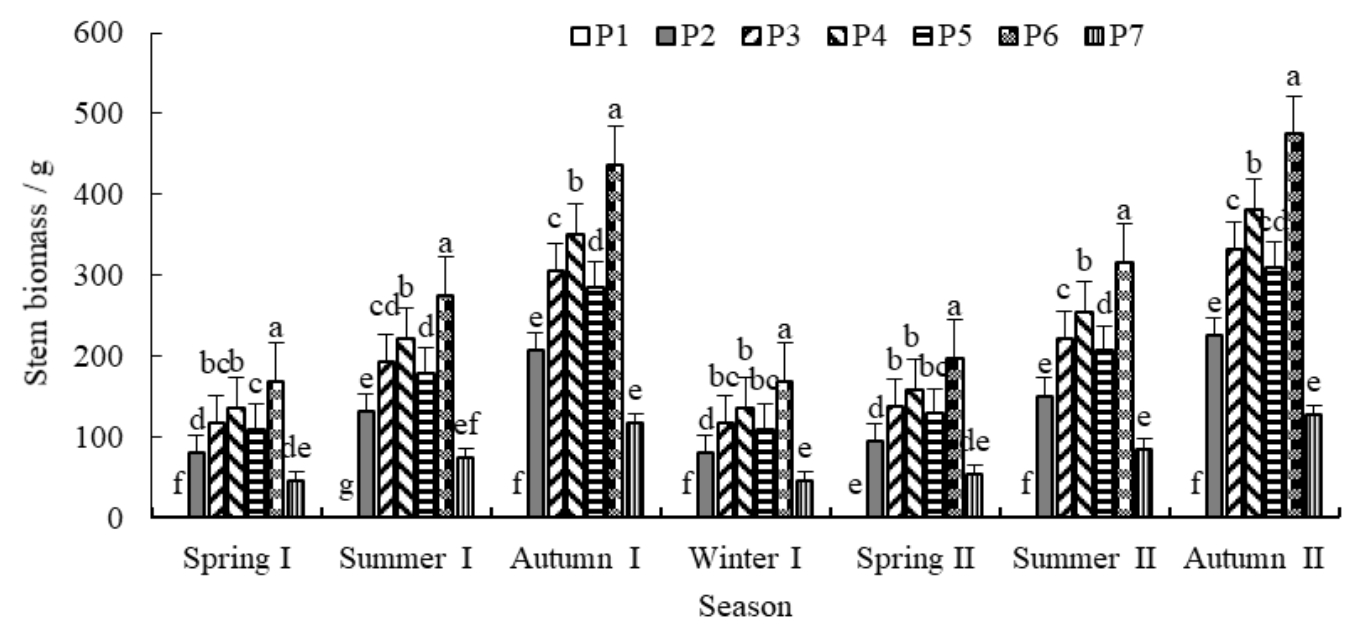

Fig. 3: Interaction of slope, vegetation type and precipitation on stem biomass of slope protection plants.

on root biomass $(p<0.01)$ in Fig. 4 . The biomass of each slope root increased significantly with an increase in vegetation type and precipitation but decreased significantly with an increase in slope gradient. The root biomass of slope protection plants increased gradually with time, and the increase in amplitude was the largest in the condition of grass and shrub mixed planting and $10 \mathrm{~mm}$ precipitation, and was sensitive to water changes with the same slope and vegetation type model. For the same vegetation type and precipitation mode, the root biomass and increase range were the largest when the slope was $45^{\circ}$.

\section{Root Shoot Ratio (R/S)}

The synergistic effect of slope, vegetation type and precipitation had a significant effect on the slope plant $\mathrm{R} / \mathrm{S}$ ( $p$
$<0.05)$. In Fig. 5 R/S was greater than 1 in the shrub single planting mode with a slope of $75^{\circ}$ and less than 1 in other modes and reached its maximum value in winter.

With the same slope and precipitation model, the R/S of the grass and shrub mixed slope ranges from $0.55-0.92$, the grass single slope is the smallest, and the shrub single slope reaches a maximum. The R/S is the largest at 15 -js (slope with $15 \mathrm{~mm}$ precipitation), and the root shoot distribution was more sensitive to low water. The R/S decreased and then increased with an increase in slope, and the resource acquisition of the root system is larger at a high slope.

\section{Sensitivity Analysis of Biomass Allocation of Vegetation under Co-operating Environment}

According to Table 2, the variation coefficient of leaf biomass

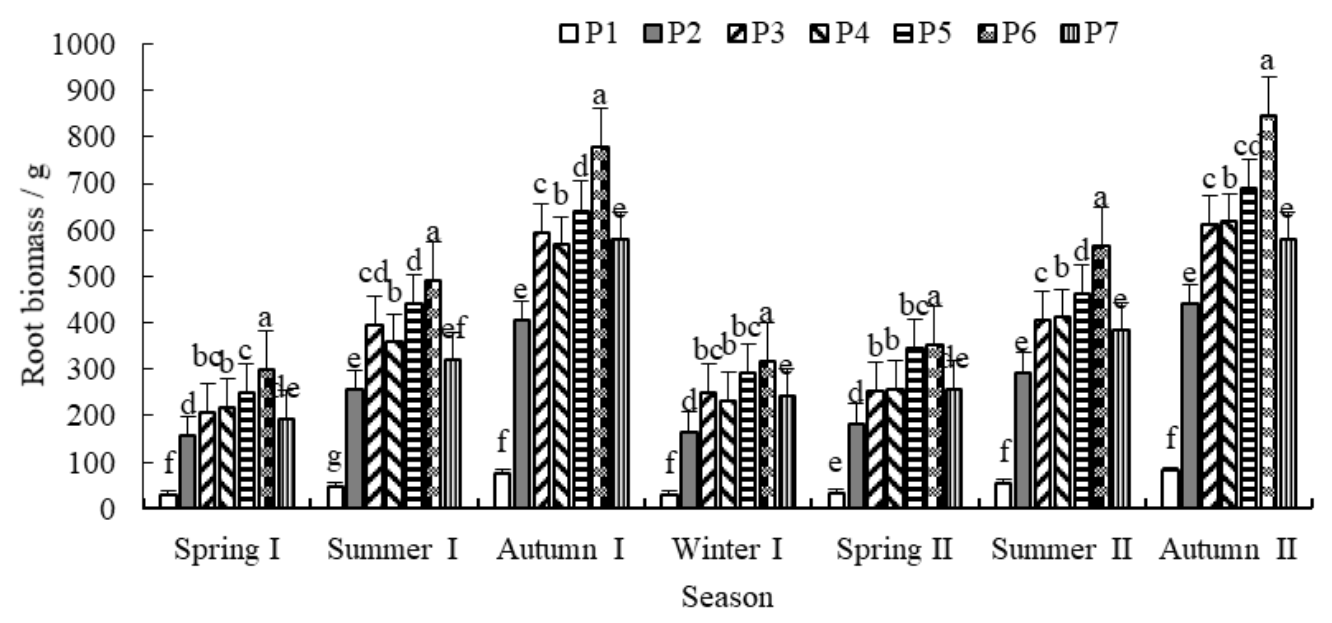

Fig. 4: Interaction of slope, vegetation type and precipitation on root biomass of slope protection plants. 


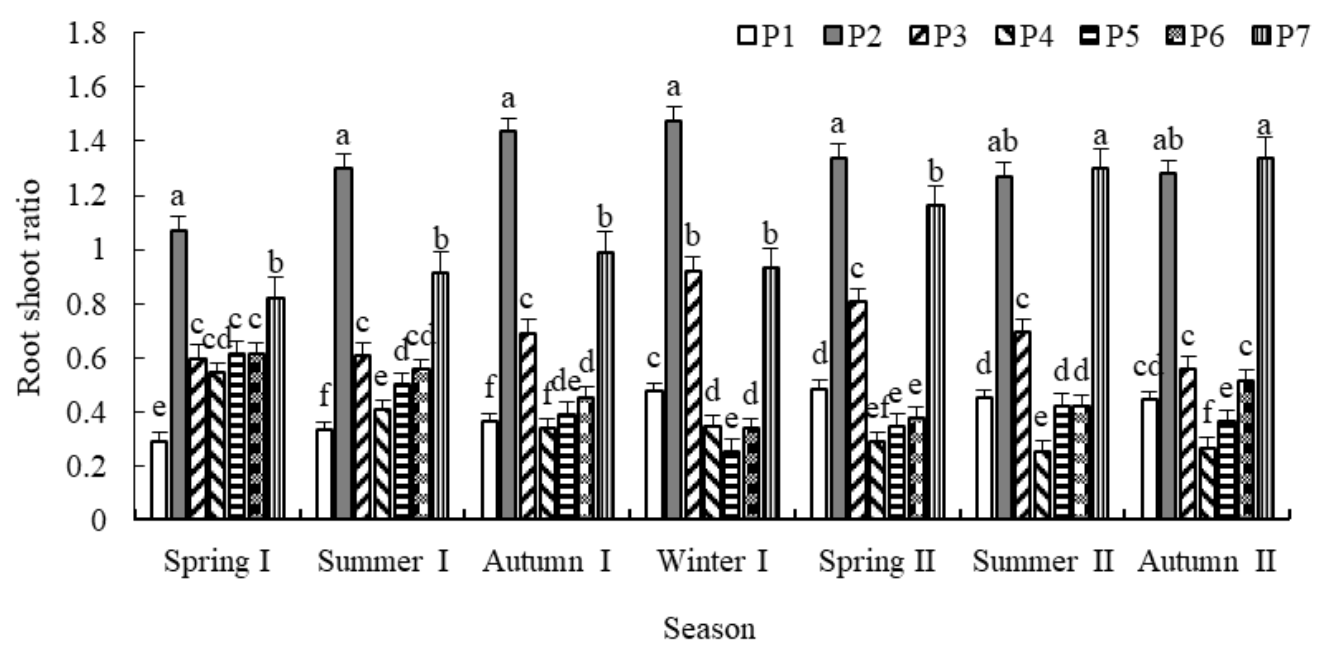

Fig. 5: Interaction of slope, vegetation type and precipitation on $\mathrm{R} / \mathrm{S}$ of slope protection plants.

ratio (LMR) in the pure grass slope with vegetation type was the largest, that is, the slope plant leaves were the most sensitive to the synergistic effect of slope, vegetation type and precipitation. The variation coefficient of the biomass ratio of each organ with the change in precipitation was LMR > root biomass ratio (RMR) $>$ stem biomass ratio (SMR), that is, the sensitivity of each organ of slope vegetation was leaf $>$ root $>$ stem for the synergistic effect of slope, vegetation type and precipitation. With an increase in slope, the coefficient of variation of the SMR with precipitation and vegetation type was unchanged, which indicates that the SMR was relatively stable for the synergistic effect of slope, vegetation type and precipitation.

\section{Allometric Growth Relationship of Aboveground and Underground Biomass under Co-Operating Environment}

Through the biomass analysis of seven slope plant organs, a significant difference between them $(p<0.05)$ was observed (Fig. 6). According to the analysis of the BGB (Below ground biomass)-ALB (Above ground leaf biomass) correlation growth index, the allometric growth indexes of the seven slopes were 1.3567, 2.0096, 1.2518, 1.3283, 1.4993,

Table 2: Sensitivity of biomass allocation of slope vegetation under co-operating environment.

\begin{tabular}{|llllllll|}
\hline Variables & \multicolumn{2}{c}{ Treatment } & \multicolumn{1}{l|}{} \\
\cline { 2 - 8 } & P1 & P2 & P3 & P4 & P5 & P6 & P7 \\
\hline RMR & 2.26 & 5.17 & 3.74 & 3.52 & 3.81 & 3.81 & 4.51 \\
SMR & 0.00 & 2.64 & 2.03 & 2.17 & 2.00 & 2.14 & 1.51 \\
LMR & 7.74 & 2.19 & 4.23 & 4.31 & 4.19 & 4.05 & 3.99 \\
\hline
\end{tabular}

1.3589 and 1.4099. According to the analysis of the ASB (Aboveground stem biomass)-BGB correlation growth index, the allometric growth indexes $\alpha$ of six slopes, except P1, were $0.8552,0.8769,0.8932,0.7527,0.8826$ and 0.7077 . According to the analysis of the ASB-ALB correlation growth index, the abnormal growth index $\alpha$ of six slopes, except $\mathrm{P} 1$, were $1.7781,1.2069,1.2188,1.2040,1.2318$ and 1.1282. The results of the constant growth test showed that the biomass growth rate of underground and aboveground plants and the root and leaf biomass of each slope showed an equal proportion relationship. The root and stem biomass ratio of the P5 and P7 slope was 0.75 in the $95 \%$ confidence interval, which revealed $\alpha=3 / 4$ constant growth relationships, that is, the distribution rate of root biomass of the P5 and P7 slope was lower than that of stem biomass, while the biomass of roots and stems of the slopes of P2, P3, P4 and P6 did not conform to the allometric growth relationship with a $3 / 4$ power index. The growth index was close to the theoretical value of 1 at the upper limit of the $95 \%$ confidence interval.

\section{Soil Driving Force Analysis of Vegetation Biomass Distribution (R/S) in Slope for Co-Operating Environment}

Through the correlation analysis of seven slope vegetation $\mathrm{R} / \mathrm{S}$ with soil nutrients, including $\mathrm{N}, \mathrm{P}, \mathrm{K}$ and organic matter, the TN content of slope soil had a significant positive correlation with the vegetation $\mathrm{R} / \mathrm{S}$ of $\mathrm{P} 2$ and $\mathrm{P} 3(p<0.05)$ but did not have a significant positive correlation with the vegetation $\mathrm{R} / \mathrm{S}$ of $\mathrm{P} 1$. The TN content of slope soil did not have a significant negative correlation with the vegetation $\mathrm{R} / \mathrm{S}$ of P4, P5 and P6 but had a significant negative correlation with the vegetation $\mathrm{R} / \mathrm{S}$ of $\mathrm{P} 7(p<0.01)$. Except for P3, no 

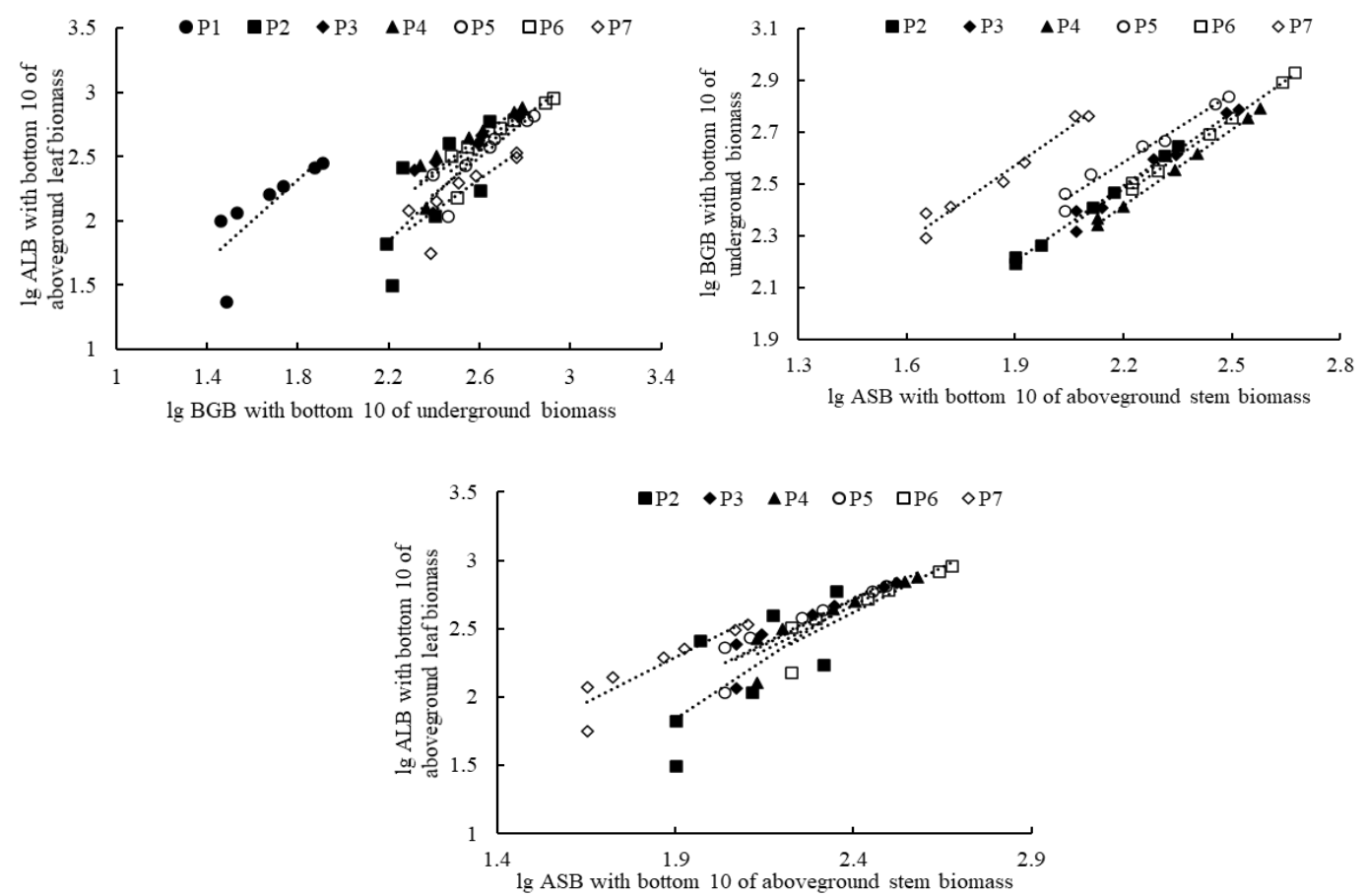

Fig. 6: RMA linear fitting relationship of slope plants ALB-BGB, BGB-ASB and ASB-ALB in double logarithmic coordinates.

significant negative correlation was obtained between the TP content of soil and the R/S of slope vegetation. For the conditions of P3, a significant negative correlation was observed between the total phosphorus content of soil and the $\mathrm{R} / \mathrm{S}$ of slope vegetation $(p<0.05)$. No significant negative correlation was obtained between the TK content of soil and the R/S of seven types of slope vegetation $(p>0.05)$. A significant negative correlation between the soil organic matter content of the $\mathrm{P} 4$ slope and the R/S of vegetation was observed. No significant positive correlation between the content of soil organic matter and the vegetation $\mathrm{R} / \mathrm{S}(p>$ 0.05 ) was obtained in $\mathrm{P} 2$ and $\mathrm{P} 3$, and no significant negative correlation between the content of the soil organic matter and the vegetation $\mathrm{R} / \mathrm{S}(p>0.05)$ was observed in P1, P5, P6 and P7 (Table 3) .

Table 3: Correlation between N, P, K content of slope soil and vegetation $\mathrm{R} / \mathrm{S}$.

\begin{tabular}{|lllll|}
\hline Resource & TN & TP & TK & Organic matter \\
\hline P1 & 0.213 & -0.301 & -0.288 & -0.109 \\
P2 & $0.049 *$ & -0.269 & -0.097 & 0.304 \\
P3 & $0.027 *$ & $-0.037 *$ & -0.217 & 0.079 \\
P4 & -0.281 & -0.204 & -0.237 & $0.024 *$ \\
P5 & -0.245 & -0.215 & -0.257 & -0.149 \\
P6 & -0.349 & -0.212 & -0.223 & -0.251 \\
P7 & $-0.010^{* *}$ & -0.392 & -0.209 & -0.201 \\
\hline
\end{tabular}

\section{DISCUSSION}

\section{Distribution Characteristics and Sensitivity of Vegetation Biomass in Slope Protection Under Co-Operating Environment}

Biomass allocation is affected by biological and abiotic factors, and balanced allocation enables plants to reach the optimal state of resource acquisition to improve their survival fitness (Wang et al. 2019). The relationship between plant biomass and species richness exhibits the hump type, and certain interspecies competition is beneficial to the increase in plant biomass (Mason et al. 2017). In this study, the effect of the mixed planting mode of grass and shrub on the community plant biomass was higher than that of a single herb or shrub. Different slopes will significantly affect the distribution of water and nutrients on slopes, which causes a difference in vegetation growth (Vaezi et al. 2017). Plant biomass decreased with an increase in slope for different slope modes, which was consistent with the results of Huang Meifen et al. (2009). The higher gradient precipitation model was more conducive to the accumulation of vegetation biomass, and the moderate increase in precipitation would improve the photosynthetic capacities of plants (Huang et al. 2009, Hsu et al. 2012).

The root shoot ratio is an important index for measuring plant growth, especially the plant response to soil nutrients 
and water states (Li et al. 2019). In this study, the root shoot ratio of the plant for the condition of grass-shrub mixed planting was higher than that for the condition of herb single planting but lower than that for the condition of shrub single planting. For the condition of mixed planting, plants tend to allocate more photosynthetic products to the aboveground parts under the competitive pressure on growth space and light resources (Wang et al. 2019). On the other hand, the distribution mode of plant biomass is not only affected by the external environment but also limited by its size (Husáková et al. 2018). The research of Ledig et al. (Ledig \& Perry 1966) showed that the root-shoot ratio of herbage decreased with growth, while that of woody plant seedlings yielded the opposite results. Low precipitation and high slope will cause water or nutrient utilization pressure, and plants will weaken the growth of the aboveground part to a certain extent, and strengthen the absorption of water and nutrients by increasing the number of roots, root activity and root shoot ratio (Yang et al. 2018).

Studies have shown that leaf traits are closely related to plants' acquisition and utilization of resources and are highly sensitive to environmental changes on different scales (Picotte et al. 2009). This finding is consistent with the results of this study, the most sensitive organ of biomass allocation in plants to the synergistic effect of slope, vegetation type and precipitation was the leaf. The stable distribution of stem and root biomass ensured the adaptability of slope protection plants to environmental change in the recovery process, which reflected the sensitivity and integrity of each organ of the plant to collaborative change in interactive environmental factors and showed that slope protection plants had a certain self-protection and regulation ability to environmental stress.

\section{Allometric Growth Relationship of Plants Under Co-Operating Environment}

This study showed that the underground and aboveground biomass and root and leaf biomass of the plants on slopes had a constant growth rate relationship, which was consistent with previous research results on the same growth rate of the biomass among the components of plants, which reflected the general law of resource allocation strategy for plant acquisition and the allocation strategy of plants (Vasseur et al. 2018). Habitat conditions, phylogenetic history and interspecific relationships drive allometric growth relationships of plant components on different spatial and temporal scales, and the regional habitat gradient formed by water and soil affects the allocation pattern of biomass of plant components (Wills et al. 2016, Jiang \& Wang 2017). In this study, the root and stem biomass of slope plants with different rainfall and slope is $\alpha$ $=3 / 4$ of heterogenic growth, while the biomass of plant roots and stems of each slope were not consistent in the interactive condition. The same slope was obtained among the roots and leaf organs of all slopes, that is, the allometric growth index was 0.6418 . The differences in the growth relationship among the organ components of plants for different environmental models further confirmed that plants could achieve and maintain maximum growth by regulating the biomass distribution in different organs due to the influence of external environmental conditions (Wang et al. 2019).

\section{Response Characteristics of Plant Biomass Allocation (R/S) to Soil Factors Under Co-Operating Environment}

As the main environmental factor that restricts the growth of vegetation, the soil factor also indirectly affects the distribution trend of plant biomass (Yuan et al. 2020). TN of soil had a significant positive correlation with the R/S of P2 and P3 vegetation, which may be due to the dense shallow root system of herbage that concentrates on the surface of the soil. In addition, the deposition of organic matter in soil accelerated the absorption, transportation and circulation of nitrogen and other nutrients in the soil, which promotes the increase in aboveground biomass of plants, while perennial shrubs need to store more material and energy in the underground part to ensure that the plants would germinate again next year. Certain inter-species competition would also promote plants to increase the root shoot ratio to occupy the space and resource advantage (Zuo et al. 2018). However, a very significant negative correlation with the R/S of P7 vegetation was observed. Some studies have shown that high slope will cause a large degree of variation in soil water or nutrients, while plants can enhance the absorption and utilization of water and nutrients by adjusting the morphological characteristics, such as the root shoot ratio (Ledig \& Perry 1966, Yang et al. 2018). The increase in the soil $\mathrm{pH}$ value can improve the utilization rate of phosphorus in the soil, and the extension of the plant root system and the accumulation of biomass can be promoted by the alkalinity of soil $\mathrm{pH}$ value in a proper range (Ma et al. 2012). In this study, the proportion of base material mixed with cement was weak alkaline, which promoted the absorption of phosphorus by plants to a certain extent and showed a significant negative correlation with the slope vegetation R/S.

\section{CONCLUSION}

1. A significant effect on leaf biomass, stem biomass, root biomass and $\mathrm{R} / \mathrm{S}$ of slope vegetation $(p<0.05)$ was observed under co-operating environment. The biomass of leaf, stem and root increased significantly with the increase in vegetation type and precipitation but decreased significantly with an increase in slope. 
The root shoot ratio was less than 1 , except for the mode of shrub unicast and a slope $75^{\circ}$, and reached the maximum value in winter, which indicates that the spatial distribution of the biomass of slope protection plants and their response mechanisms to environmental factors were quite different.

2. The variation coefficient of LMR was the largest under co-operating environment, and the sensitivity of the biomass allocation of each organ was leaf biomass ratio $>$ root biomass ratio $>$ stem biomass ratio, which indicated that leaf biomass was most susceptible to the environmental model, while stem biomass was less affected.

3. Significant differences in the biomass of each organ of plants on different slopes $(p<0.05)$ were obtained. The root and leaf showed an isokinetic growth relationship $(\alpha=1)$, while the plant roots and stems showed an allometric growth relationship ( $\alpha=3 / 4)$ due to the synergistic effect of precipitation and slope (P5 and P7 slopes). The vegetation on each slope had the same slope, and their allometric growth index was 0.4109 (root-leaf), 0.5961 (stem-root) and 0.6418 (stem-leaf).

4. The correlation analysis of the influence of soil factors on the biomass allocation $(\mathrm{R} / \mathrm{S})$ revealed that the TN of soil was significantly correlated with the R/S of vegetation $(p<0.05)$ due to the synergistic effect of vegetation type and slope (P2, P3 and P7 slope); the TP of soil and R/S of vegetation of P3 were significantly negatively correlated $(p<0.05)$; while the remaining slope soil nutrient and vegetation $\mathrm{R} / \mathrm{S}$ had no significant correlation $(p>0.05)$.

5. The content of soil nitrogen and phosphorus were the key soil driving factor affecting the distribution pattern of plant biomass. The resource allocation characteristics of different vegetation and its response to soil factors had specificity.

\section{ACKNOWLEDGEMENTS}

This research was supported by the National Key R\&D Program of China (2017YFC0504902), National Natural Science Foundation of China $(51678348,51979147)$ and the Natural Science Foundation of Yichang City (A21-3-007), the Natural Science Foundation of Hubei Province (2020CFB317) and the CRSRI Open Research Program (CKWV2019753/KY).

\section{REFERENCES}

Cao, Y. and Chen, Y.M. 2015. Biomass, carbon and nutrient storage in a 30-year-old Chinese cork oak (Quercus variabilis) forest on the south slope of the Qinling mountains, China. Forests, 6: 1239-1255.
Daniel, P.B., Jorge, Á.F., Neil, C.H., Jorge, L. and Carlos, C.M. 2014. Winter cereal root growth and aboveground-belowground biomass ratios as affected by site and tillage system in dryland Mediterranean conditions. Plant and Soil, 374: 925-939.

Fang, J.M., Wu, F.Z., Yang, W.Q., Zhang, J. and Cai, H.X. 2012. Effects of drought on the growth and resource use efficiency of two endemic species in an arid ecotone. Acta Ecologica Sinica, 32(4): 195-201.

Hsu, J.S., Powell, J. and Adler, P.B. 2012. Sensitivity of mean annual primary production to precipitation. Global Change Biology, 18(7): 2246-2255.

Huang, M.F., Xu, C., Cao, H.Y., Hang, X.S., Yuan, F.J., Yin, Y.C., Zhong, S., Yin, Z.F., Kui, J.X., Luo, Z.R., Duan, X.H., Wang, H.X., Dai, C.L. and Guan, R.F. 2009. Vegetative growth of Eupatorium adenophorum in different habitats. Chinese Journal of Tropical Crops, 30(10): 14291436 (in Chinese).

Husáková, I., Weiner, J. and Münzbergová, Z. 2018. Species traits and shoot-root biomass allocation in 20 dry-grassland species. Journal of Plant Ecology, 11(2): 273-285.

Jiang, Y. and Wang, L. 2017. Pattern and control of biomass allocation across global forest ecosystems. Ecology and Evolution, 7(14): 54935501.

Ledig, F.T. and Perry, T.O. 1966. Physiological genetics of the shoot-root ratio [C]//Proceedings of the Society of American Foresters Annual Meeting. Washington, USA: Society of American Forester, 39-43.

Li, C.B., Zheng, Z., Peng, Y.F., Nie, X.Q., Yang, L.C., Xiao, Y.M. and Zhou G.Y. 2019. Precipitation and nitrogen addition enhance biomass allocation to aboveground in an alpine steppe. Ecology and Evolution, 9(21): 12193-12201.

Ma, Q., Yue, L.J., Zhang, J.L., Wu, G.Q., Bao, A.K. and Wang, S.M. 2012. Sodium chloride improves photosynthesis and water status in the succulent xerophyte Zygophyllum xanthoxylum. Tree Physiology, 32: 4-13.

Mason, C.M., Goolsby, E.W., Davis, K.E., Bullock, D.V. and Donovan, L.A. 2017. Importance of whole-plant biomass allocation and reproductive timing to habitat differentiation across the North American sunflowers. Annals of Botany, 119(7): 1131-1142.

Norton, D.A. and Young, L.M. 2016. Effect of artificial shade and grazing removal on degraded grasslands: Implications of woody restoration for herbaceous vegetation. Ecological Management \& Restoration, 17(2): 140-146.

Picotte, J.J., Rhode, J.M. and Cruzan, M.B. 2009. Leaf morphological responses to variation in water availability for plants in the Piriqueta caroliniana complex. Plant Ecology, 200: 267-275.

Vaezi, A.R., Zarrinabadi, E. and Auerswald, K. 2017. Interaction of land use, slope gradient and rain sequence on runoff and soil loss from weakly aggregated semi-arid soils. Soil \& Tillage Research, 172: 22-31.

Vasseur, F., Exposito-Alonso, M., Ayala-Garay, O. J., Wang, G., Enquist, B.J., Vile, D., Violle, C. and Weigel, D. 2018. Adaptive diversification of growth allometry in the plant Arabidopsis thaliana. Proceedings of the National Academy of Sciences of the United States of America, 115(13): 3416-3421.

Wang, D.Y., Zun, Q.J., Wang, J. and Huang, W.Y. 2020. Three-dimensional geonet ecological slope protection technology and its engineering application. IOP Conference Series Materials Science and Engineering, 794: 012055.

Wang, Q.W., Daumal, M., Nagano, S., Yoshida, N., Morinaga, S.I. and Hikosaka, K. 2019. Plasticity of functional traits and optimality of biomass allocation in elevational ecotypes of Arabidopsis halleri grown at different soil nutrient availabilities. Journal of Plant Research, 132(2): 237-249.

Willis, A., Harris, P.J.C., Rodrigues, B. and Sparks, T. 2016. Primary sanddune plant community and soil properties during the west-coast India monsoon. Nephron Clinical Practice, 2(1): 60-71. 
Xu, W.N., Xia, Z.Y., Zhou, M.T., Liu, D.X. and Xia, D. 2012. The vegetation concrete eco-restoration technology theory and practice. China Water $\&$ Power Press, Beijing (in Chinese).

Yang, Y., Dou, Y.X., An, S.S. and Zhu, Z.L. 2018. Abiotic and biotic factors modulate plant biomass and root/shoot $(\mathrm{R} / \mathrm{S})$ ratios in grassland on the Loess Plateau, China. Science of the Total Environment, 636: 621-631.

Yuan, Y., Xiong, D.H., Wu, H., Zhang, S., Zhang, B.J., Dahal, N.M., Liu, L., Li, W.X., Zhang, W.D. and Shi, L.T. 2020. Spatial variation of soil physical properties and its relationship with plant biomass in degraded slopes in dry-hot valley region of Southwest China. Journal of Soils and Sediments, 20: 2354-2366.

Zhang, L.Y., Liu, D.X., Xu, W.N. and Tong, B. 2017. A study on the change of three functional microorganism quantities in habitat substrate under freezing-thawing cycles. Journal of Glaciology and Geocryology, 39(5): 1122-1129 (in Chinese).

Zuo, Y.L., Wang, Z.M., Xi, X.Q., Xiang, S. and Sun, S.C. 2018. Plant biomass allocation strategies of the dominant species in an alpine meadow of northwestern Sichuan, China. Chinese Journal of Applied \& Environmental Biology, 24(6): 3-11 (in Chinese). 